\title{
Using a PRISM for Reflecting: Providing Tools for Study Abroad Students to Increase their Intercultural Competence
}

\section{Tracy Rundstrom Williams}

Texas Christian University

\begin{abstract}
:
Numerous studies have shown that simply being in another culture does not guarantee the development of intercultural competence. Students need guidance to seek out opportunities to engage and to make sense of those experiences. Reflection has become a popular methodology to assist students with this. Unfortunately, students often do not know how to do reflective writing or do not have cultural incidents to write about. This research examines one approach to guiding reflection: the use of prompt questions to elicit thoughtful responses and the integration of readings to provide context and grounding. This study demonstrates that reflective writing can be an effective tool for intervening in student learning abroad if done with structure and intentionality.
\end{abstract}

\section{Intercultural Competency, Intervention and Study Abroad}

Much recent research in the field of international education has explored students' development of intercultural competence during study abroad experiences (AAC\&U 2013, Vande Berg et al., 2009; Deardorff, 2006; Olson et al., 2006). Intercultural competence, generally defined as the ability to adapt behavior and communication to intercultural contexts using a variety of skills and knowledge (Deardorff, 2011; Bird et al., 2010; Bennett, 2009; Deardorff, 2006; Gertsen, 1990), seems like a natural outcome of spending time abroad. However, correlations between intercultural competence and study abroad have been inconsistent (Behrnd \& Porzelt 2012), leading many to conclude that studying abroad alone does not ensure students develop intercultural competence. Therefore, research on intercultural learning has explored variables in the study abroad experience that could impact outcomes.

One line of research has investigated the impact of length of stay. Much research indicates that longer duration generally leads to greater gains in intercultural development (Behrnd \& Porzelt, 2012; Vande Berg et al., 2009; Kehl \& Morris, 2007; Medina-López-Portillo, 2004), although some studies have shown that even short-term programs can have significant and meaningful impacts on students' intercultural development (Jackson, 2008; Anderson et al.., 2006; Lewis \& Niesenbaum, 2005; Chieffo \& Griffiths, 2004; Dwyer, 2004).

Other studies, however, have found that duration alone does not account for variations in results. Williams (2005) found students who studied abroad for a semester generally had greater gains in intercultural communication than students on campus, but the biggest predictor for intercultural communication gains was the amount of intercultural interactions students had. 
Pedersen (2010) concurs, commenting that simply sending "students to a location abroad for academic study is not sufficient toward facilitating the larger goal of creating effective global citizenship" (p. 71) and that specific learning outcomes need to be made in order to enhance existing programs. Behrnd and Porzelt (2012) go further to critique the current system of study abroad, particularly the "decision makers at universities [who] often ignore this fact and are not aware that intercultural learning by being abroad works only under certain conditions," including meaningful preparation and intercultural training (p. 213).

As such, educators in study abroad have been increasingly interested in the ways they can help facilitate learning, and recent research has explored the effectiveness of intervention (Behrnd \& Porzelt, 2012; Deardorff, 2011; Hunter, 2008; Huq \& Lewis, 2012; Pedersen, 2010; Vande Berg et al., 2012). Many suggest programs will be more effective if they "do not rely on the haphazard chance of students engaging in this process on their own, but instead very intentionally organize learning activities to encourage it" (Hunter, 2008, p. 99). Moore (2010) concurs, stating "these transformative effects depend on careful planning and execution, on avoiding the tendency to fall back on the adage that 'every experience is educational,' [and] on pushing students - and faculty - to think rigorously and extensively about the intersections between theory and practice" (p. 11). Vande Berg et al.. (2009), for example, found the use of a cultural mentor onsite to be an effective intervention leading to increased intercultural development (p. 25). Similarly, Pedersen (2010) found students who participated in "intercultural pedagogy" (with intentional learning opportunities framed around intercultural learning outcomes) during their study abroad experience had greater gains than students who studied abroad without such intervention (p. 76).

However, even with positive correlations between interventions and intercultural competency, there is still ambiguity in defining the specific pedagogical practices which lead to intercultural learning goals. While Pedersen (2010) found significant gains in students who studied abroad when there was some form of intercultural pedagogy, the "relationship between the pedagogy utilized in study abroad and student outcomes such as intercultural effectiveness [remains] largely unanswered" (p. 71). Therefore, identifying which pedagogical approaches best help study abroad students develop intercultural competency is a valuable contribution to the field.

\section{Reflection as an intervention for developing intercultural competence}

Reflection is a much-promoted practice for increasing students' learning from experiential activities. In his theory of experiential learning, Kolb states that for learning to take place, the experience has to be transformed into knowledge by means of action or reflection (1984). Reflection can help students connect their experiences and feelings to frameworks and theories. It can help students 'find voice' (Hertz, 1996, p. 3). Reflection takes the experience from inside the head to the outside world (Oatley and Djikic, 2008).

Reflective writing, or journaling, has been particularly linked to the cultural learning process. Wagner and Magistrale (2000) promote writing as the primary process to "help you develop the ability to interpret your everyday cultural experiences" (p. 23). Similarly, McAllister et al. find "reflective thinking leading to reflective judgment appears to be an important aspect of cultural competence; in fact, it may be more critical than some other aspects, like possessing specific 
knowledge or having a particular kind of attitude towards specific groups of people" (2006, p. 370). Paige et al. note journals can "serve as a record of experiences, provide a reference for culture and language learning and development, or help...cope with feelings and emotions" (2004, p. 115). Indeed, Wagner and Magistrale (2000) find writing has a number of important purposes, particularly in new cultural settings, including:

- Learning: "the more you write, the more opportunity you will have to understand better your foreign culture, your native culture, yourself” (p. 25);

- Organizing: "Combining invisible thoughts with the physical action of forming words on paper helps you discover, remember, and organize what you are thinking” (p. 26;

- Developing Perspective: "Your writing helps you attain a certain distance - or perspective" (p. 26); and

- Communicating: "Writing brings order to the stream of conflicting information that our brain continually receives from our senses" (p. 27).

Paige et al. (2004) concur, noting journaling while abroad can include a variety of styles, including recording your impressions of the new place, describing your experiences, narrating stories, and expressing feelings.

Unfortunately, for both students and faculty, reflection is not necessarily intuitive. Students may not know how to do reflection, may resist doing it, or may fall into simplistic personal narratives when they attempt it (Moore, 2010; Alvesson \& Skoldberg, 2000; Boud \& Walker, 1998; Finlay, 2002; Lewis, 2000). Paige et al. (2004) note, "one of the main reasons people give up on journaling is that they find the process of writing down every detail of their experience overwhelming and sometimes quite boring” (p. 116). Often, unstructured journaling ends up stifling creativity, learning, and good writing.

Similarly, faculty may not know how to guide students through reflection. Many researchers point to the difficulties faculty face when teaching and assigning reflection in academic contexts (Finlay \& Gough, 2003; Hsiung, 2008; Brockbank \& McGill, 1998; Larivee 2008). Smith (2011) notes reflection exercises often do not produce the desired results because they lack "clarity of purpose" and "rely heavily on students' own, uncontextualized accounts of events that do not directly discern the learning that takes place” (p. 219).

To affect learning, we must look more critically at the notion of reflection and the practice of journaling. Reflection does not guarantee learning, and the act of reflection in itself is not an outcome (Burton, 2006). Certainly, "writing is thinking" (Oatley and Djikic, 2008, p. 9), as it involves articulating vague ideas in words. But putting thoughts into words does not necessarily mean students are learning. Students demonstrate learning when the reflection leads to meaningful connections, new schemas or models, and thoughtful critiques. A simple account or testimony of an event is not sufficient; a learning reflection produces a transformation in perspective (Moon 1999), such as seeing events from another person's point of view, critically analyzing thoughts and reactions to events, and/or situating the experience and reactions in a social and cultural context. 
It becomes important, therefore, to characterize or categorize the degree of learning, analysis, or transformation generated by reflection. Hatton and Smith (1995), for example, propose the following framework, with descriptive writing being the most simplistic and critical reflection being the most developed in terms of learning demonstrated:

Descriptive writing: description with no discussion nor evidence of reflection.

Descriptive reflection: mostly descriptive; the possibility of alternative views is accepted but most reflection is from one perspective.

Dialogic reflection: demonstrates a 'stepping back' from events and actions; shows some exploration of self, others, events and actions; recognition that different qualities of judgment and alternative explanations may exist for the same material. The reflection is analytical or integrative, though it may reveal inconsistency.

Critical reflection: demonstrates an awareness that actions and events are located within and explicable by multiple perspectives; awareness that actions and events are located in and influenced by multiple historical and socio-political contexts.

Another approach, by Smith (2011) examines the foci, or domains, of reflection, to differentiate the development or learning. Smith proposes students should try to move outward, from thinking only about themselves (personal reflection), to exploring other perspectives (interpersonal reflection), to making sense through contextualization of concepts and theories (contextual reflection), and finally critically examining themselves and their paradigms (critical reflection) (p. 217).

These models suggest insightful reflection and transformative learning come from identifying and explaining experiences from multiple perspectives, critically analyzing one's thoughts and reactions to events, and placing experiences in broader contexts. Interestingly, there is a similar progression of development in intercultural learning, according to the AAC\&U (Association of American Colleges and Universities) VALUE Rubric on Intercultural Knowledge and Competence. The rubric, created by a team of faculty experts from colleges and universities across the U.S. lists six cognitive, affective and behavioral skills and characteristics "that support effective and appropriate interaction in a variety of cultural contexts" (Bennett, 2009, p. 97). These six characteristics include two cognitive components (cultural self-awareness and knowledge of cultural frameworks), two behavioral components (empathy and verbal and non-verbal communication), and two affective components (curiosity and openness). The AAC\&U rubric suggests four levels of achievement, from benchmark to capstone, for each of the six characteristics, which tend to follow these themes:

Benchmark: Shows minimal awareness of own cultural rules and biases, is unable to negotiate shared meaning in interactions, interprets experiences through own worldview without question or awareness of own judgment, and shows minimal interest in learning about other cultures.

Milestone 2: Identifies own cultural biases but unable to respond with any other worldview, demonstrates partial understanding of other cultural values, aware of misunderstandings but 
unable to negotiate share meaning, has difficulty suspending judgment of others, and asks simple or surface questions about other cultures.

Milestone 3: Recognizes new perspectives about own cultural rules and biases, demonstrates adequate understanding of elements of others' cultures, recognizes more than one worldview, begins to negotiate shared meaning in intercultural interactions, asks deeper questions about other cultures and begins to seek out answers, begins to initiate and develop interactions with culturally different others while suspending judgment.

Capstone: Articulates insights into own cultural rules and biases, demonstrates sophisticated understanding of the complexity of cultural elements, interprets experiences from more than one worldview, able to negotiate shared meaning in intercultural communication, asks complex questions and seeks out answers, suspends judgment when interacting with culturally different others.

These resources highlight a number of important features which can be used to demonstrate student learning in study abroad reflections. Both reflective writing learning models and learning goals for intercultural competence should inform a rubric for intercultural reflection. With this in mind, I propose the following rubric for evaluating reflective work on intercultural experiences:

\section{Intercultural Reflection Rubric}

1. Observation: The reflection is simply descriptive; does not attempt to understand, explore, or make meaning of experiences or observations. The reflection does not recognize other points of view, is unable to suspend judgment of others, or may be critical or negative toward the other.

2. Growing Awareness: The reflection is mostly descriptive and may show basic attempts to understand or learn more about observations. The reflection begins to recognize other points of view but in simplistic and superficial ways; prefers own perspective or does not know how else to interpret or act.

3. Appreciation and Eagerness: The reflection begins to make simple interpretations. The reflection may list simple new understandings or simplistic personal growth and change. The reflection demonstrates an emerging desire to learn or a sense of wonder to find answers to questions. The reflection shows increasing recognition of other points of view and shows growing respect for differences. The reflection begins to validate differences or attempts simple explanations of differences.

4. Emerging Comprehension: The reflection attempts to articulate more in-depth interpretations though it may reveal inconsistency. The reflection demonstrates an increasing desire to learn and may list ways knowledge is incomplete. The reflection describes and respects other perspectives but may not reach level 5 . The reflection attempts to explain differences in more depth, or draw connections and conclusions without fully exploring them.

5. Intercultural Consciousness: The reflection shows complex interpretations and thoughtful insights about self and culture and discusses how to apply learning. The reflection shows a strong desire to learn more and may offer ideas for gaining more knowledge. The reflection describes other perspectives in depth and recognizes and respects 
the complexity of culture. The reflection explains differences in depth and/or describes incidents through the other's point of view.

While the highest level is intercultural consciousness, this rubric identifies and validates the steps in between and provides some explanation of the variance between each. As such, we can better describe and identify reflective work that demonstrates development in intercultural competence.

\section{Facilitating Students' Reflective Work}

Even with a framework for quality reflection, students may still struggle to produce meaningful work, indeed to learn from their experiences. How do we help students move from observation to intercultural consciousness?

One idea is the critical incidents approach. A critical incident is a story with a climax, dilemma, or issue for which the teller needs to ascribe some meaning (Fitzgerald, 2001). The critical incident approach in intercultural contexts encourages students to retell stories with focus on describing and understanding the cultural difference or miscommunication. "Critical incident approaches are commonly used in cultural competency training to foster critical thinking and transformative learning" (Brookfield, 1990). Asking students to structure the telling of experiences as "critical incidents" helps them focus on finding meaning or resolving ambiguity in intercultural situations.

Critical incidents provide a focus for recounting a story by providing a structural basis for analysis and meaning-making (Fitzgerald, 2000). Through the telling and retelling of the incident and the subsequent discussion, "the person's understanding of the concept of culture and strategies to address cultural issues can be more fully explored” (Laws \& Fitzgerald, 1997, p. 36).

Unfortunately, students may not know how to turn their everyday interactions into critical incidents. In fact, part of the struggle of helping students learn from their experiences abroad is helping them even see the opportunities for learning. Students may be oblivious to the subtleties of differences in their host culture or may not know how to restructure and retell their encounters with others as critical incidents. Alternatively, and perhaps more worrisome, students may not even have enough encounters with locals to create critical incidents, often due to a lack of language skills, a propensity to spend time with other Americans, or a lack of leisure, un-programmed, and technology-free time.

An alternative is the Refraction model, proposed by Pagano and Roselle (2009). "Refraction highlights the importance of using guiding questions and faculty interaction to encourage students to use written reflection ... to truly think" (p. 220). Pagano and Roselle implemented this approach in an international internship and service learning class. Students were encouraged to develop questions they wanted to explore, such as "What factors affect ? ?" and "Under what conditions does affect ?? (p. 222). Such guiding questions provide a framework for students to organize their experiences and begin critically thinking. From this, students can then move into the step of refraction, in which they actively offer solutions to problems, engage with others, and change mental models. 
This approach, however, relies on the student having a great deal of structured and related interactions to develop and answer the types of questions Pagano and Roselle propose, such as "What factors affect how PR firms are being used to promote European identity?" (2009, p. 227). In addition, this approach, by nature of honing in on a focused question, also misses the opportunity to develop intercultural competency which is focused on more broad-based and transferable knowledge and skills.

If the goal is to help students develop knowledge and skills to adapt to future intercultural interactions and to have truly transformational experiences, we have to help students connect everyday experiences to deeper insights. To use reflection in that manner - in other words, to develop intercultural competency - students need enough fluidity to have natural and organic experiences and interactions as well as enough structure to help them make sense of those experiences.

\section{Using a PRISM}

I propose an approach that offers students these opportunities. In this approach, students are given videos and readings to provide context and frameworks for interpreting their experiences, prompts to engage and interact with others, and structured questions to provide guidance for reflection. I call this approach the PRISM, because this tool provides students the opportunity to go beyond the visible, and see their host culture and its people in nuanced and complex ways (Williams, forthcoming).

The PRISM helps students get Prepared, make it Relevant, get Involved, make Sense, and make it Matter. In this approach, I provide videos to get them prepared and readings to make it relevant, which form the context for their learning. Next I ask them to get involved by giving them assignments to do with people in their community, which forms the opportunity for learning encounters. Then I provide guided questions for them to structure their thinking and make sense of their encounters. Lastly, I encourage them to practice what they have learned by making it matter, leading to their next encounters being richer and deeper.

The goal of the PRISM approach is to provide "bounded freedom" in their assignments: opportunities for exploration with some specifications and parameters that provide some framework. Students using this approach are studying in various locations around the world, so the preparation readings, involvement assignments, and prompts for making sense have the flexibility and openness to be adapted to any location (and to the students' interests) while being grounded in intercultural learning goals.

To test the effectiveness of this pedagogy, I sought to answer the following research question:

Is the PRISM approach to reflection more effective than unstructured reflection in helping students develop intercultural competence?

While there are five elements of this pedagogy, for the purpose of this study, I will focus on the reflective writing piece, which incorporates the readings that help Make it Relevant and the guided prompts provided for them to Make Sense. 


\section{Methodology}

I tested this question in a one-credit, semester-long study abroad course. At Texas Christian University (TCU), students studying abroad for a semester were required take the course UNPR 20201: Engaged Global Citizenship to assist them in developing their intercultural competence while abroad. The course met twice before departure, and the remainder of the work was done on-site (while the instructor was on the home campus), with weekly reflection papers submitted online. With Institutional Research Board (IRB) approval from TCU, in the fall 2014 class I randomly assigned students into one of two sections. Both sections had the same readings to complete and the same number of reflection papers to write. However, the two sections differed in how the students' comprehension of the reading was evaluated and how the prompts for the reflection were structured. In the control section, students had quizzes over the reading and were given an unstructured, open reflection prompt: write a thoughtful reflection about your cultural learning for the week. Students in the PRISM section were given more structured reflection prompts related to the intercultural learning goals of each week, such as What values, historical events, or infrastructures have you discovered that influence the ways people in your host culture behave or structure their lives? In what ways have you been impacted by listening to others' stories? How have you changed your way of thinking? They were also instructed to incorporate the assigned reading into their reflections.

In addition to using the Intercultural Reflection Rubric to measure students' intercultural development, I also used the Intercultural Effectiveness Scale (IES), an instrument which evaluates individuals' competencies for effective interaction with people of other cultures. The Intercultural Effectiveness Scale (IES) is a 52-item self-assessment which measures three critical competency areas of intercultural effectiveness: continuous learning, interpersonal engagement, and hardiness (Mendenhall, et al., 2012). Within each of these three competency areas are two sub-dimensions: continuous learning includes self-awareness and exploration, interpersonal engagement includes global mindset and relationship interest, and hardiness includes positive regard and emotional resilience. The IES provides a score from $1-6$ for each of these competencies and sub-dimensions, as well as an overall score. The instrument, which has a high reliability $(\alpha=0.86$ according to Portalla \& Chen 2010) and validity (Mendenhall, et al., 2012), is used extensively by educational institutions for analysis such as pre- and post-measurements for changes in intercultural competencies.

As noted above, the IES provides scores on each of the dimensions and an overall score ranging from 1 (low) to 6 (high). While each of these dimensions could be explored, for the purposes of this study, which is primarily a qualitative study, I looked at students' overall scores for a sense of their starting points and potential for growth. Because I was particularly focused on students' development of intercultural competency during their study abroad experience, I decided to focus this study on students who had a 3 or lower on the IES to see how beginner-level students developed and articulated their intercultural competence with or without the help of the PRISM methodology.

In the fall class of 36 students, 15 students scored between $1-3$ on the IES (seven in the control section and eight in the PRISM section). While this is a small sample size, it provides an opportunity for a case study investigation from both a quantitative and qualitative view. 
For each of these 15 students, three of their essays were examined: an essay submitted at the beginning of the semester (about two to three weeks after arrival), one around the middle of the semester, and one towards the end of the semester. Using the Intercultural Reflection (IR) rubric described above, a graduate student and I both scored essays in a blind review process giving each essay a score of 1-5 (1 = Observation, 2 = Growing Awareness, 3 = Appreciation and Eagerness, 4 = Emerging Comprehension, 5 = Intercultural Consciousness). I also recorded the students' posttest IES scores. I then compared the two sections on several dimensions to determine if there was a difference in their development of intercultural competence.

\section{Results: A Quantitative Look}

Overall, the IR scores for the essays in the PRISM section were higher than scores for the essays in the control group. A t-test shows the mean scores for all the scored essays in the two groups were significantly different $(p<0.01)$. The mean score for all essays in the PRISM section was 3.42 while the mean score for the control group was 2.52 .

In addition, the PRISM students showed a greater increase in IR scores than the control group. A paired t-test for the PRISM group shows a statistically significant increase from a mean of 2.5 on the initial essay to a mean 4.13 on a later essay $(\mathrm{p}<0.01)$, while a paired t-test for the control group shows no significant difference between their initial scores (mean of 2.43) and their highest later score (mean of 2.71).

Looking in depth at the initial IR scores and later scores, some important trends occur. While both groups had similar initial IR scores, later essays for the PRISM group scored higher than the control group. In the control section, all seven students received a two or a three on their first essay. One student improved two points, three students improved one point, one student did not improve, and two students decreased in points. Only two students ever received a score of four. None received a score of five. The essays that received a score of four tended to have a critical incident to analyze. For example, student $G$ was studying in Turkey witnessing dramatic political and social issues, and in his two essays which received fours he explored new knowledge and perspectives and attempted to draw in-depth conclusions. Furthermore, in the control section, the students showed no statistically significant difference between their IES pre-test (mean of 2) and their IES (mean of 3.2) $(\mathrm{p}<0.01)$. Table 1 shows the scores of the seven students in the control section.

Table 1: Control Section: Intercultural Development and Growth

\begin{tabular}{llllllll} 
Student & Essay 1 & Essay 2 & Essay 3 & IR Growth & IES Pre-Test & IES Post-test & IES Growth \\
\hline A & 2 & 3 & 3 & 1 & 2 & 3 & 1 \\
B & 2 & 2 & 2 & 0 & 3 & 4 & 1 \\
C & 3 & 3 & 2 & -1 & 2 & 4 & 2 \\
D & 3 & 2 & 4 & 1 & 1 & 4 & 3 \\
E & 2 & 1 & 2 & 1 & 3 & 4 & 1 \\
F & 3 & 2 & 2 & -1 & 1 & 3 & 2 \\
G & 2 & 4 & 4 & 2 & 2 & 1 & -1 \\
\hline
\end{tabular}


In the PRISM section, seven of the eight students received a two or a three on their first essay. One student received a four on the first essay. All students improved their IR scores. Five improved one point, one improved two points, and two students improved three points. Furthermore, in the PRISM section, the students showed statistically significant increase in their IES scores, from a mean pre-test of 2 to a mean post-test of $4(p<0.01)$. Table 2 shows the scores of the seven students in the PRISM section.

Table 2: PRISM Section: Intercultural Development and Growth

\begin{tabular}{llllllll} 
Student & Essay 1 & Essay 2 & Essay 3 & IR Growth & IES Pre-Test & IES Post-test & IES Growth \\
\hline H & 4 & 5 & 5 & 1 & 2 & 4 & 2 \\
I & 2 & 4 & 5 & 3 & 2 & 6 & 4 \\
J & 2 & 3 & 3 & 1 & 2 & 4 & 2 \\
K & 2 & 3 & 4 & 2 & 1 & 3 & 2 \\
L & 3 & 3 & 4 & 1 & 1 & 3 & 2 \\
M & 2 & 4 & 5 & 3 & 3 & 6 & 3 \\
N & 3 & 4 & 4 & 1 & 2 & 2 & 0 \\
O & 2 & 3 & 3 & 1 & 3 & 4 & 1 \\
\hline
\end{tabular}

While this is a small sample size focusing on students with a low initial IES score, the results are confirmed for students with a higher initial IES score. In a comparison of students with a 4 or higher on the IES pretest, those in the PRISM section had a mean increase of 0.70 , which is statistically significant at the $\mathrm{p}<0.01$, while those students in the control section had a mean increase of 0.33 , which was not statistically significant.

The Intercultural Reflection Rubric and the IES are different approaches to measuring intercultural learning, but the Intercultural Reflection Rubric appears to reinforce the IES instrument. Furthermore, based on both of the measures, the research shows the PRISM course increases students' intercultural learning to a greater degree than the non-directed reflection course.

\section{Results: A Qualitative Look}

A more in-depth look at the essays highlights how the rubric helps identify the students' intercultural learning and showcases the difference between the groups. To show some of the differences, I will compare an unprompted (control section) and a prompted (PRISM section) essay from the end of the semester. I will also compare a PRISM essay from the beginning of the semester to one from the end. These two comparisons will demonstrate the contrast between unprompted and prompted reflection, and the growth from beginning to end of the semester in prompted reflection. 
First, in a comparison between the reflections from students in the control section and the PRISM section, there tends to be more analysis, contextualization, and critical thinking in the PRISM section writing. As previously mentioned, in the control section, students were given a more unstructured, open instruction to write a thoughtful, reflective journal entry of $350-500$ words, reflecting on your cultural experiences for the week. Here are selections from one student's essay for the last week of the semester:

I have not discussed my other travels in my reflections yet, but I think it is an important topic. So far, I have been to Copenhagen, three cities in Ireland, Florence, and I am going to Paris in two weeks. These trips have been amazing! It is surreal that I am able to take weekend trips to these incredible places. I have experienced things I never imagined I would. I climbed to the top of the Duomo in Florence, explored the castle in Limerick, and saw the famous mermaid statue in Copenhagen. These trips have taught me many things in my time abroad.

First, I learned that I never want to stop traveling and I learned how exactly I like to travel... My trips also helped me realize how I prefer to travel. I am not a person who likes to hit as many cities as possible in a short amount of time. I would much rather spend a longer amount of time in the same city. I do not like being rushed if I am trying to enjoy a new city. Therefore, I like spreading out an itinerary over a few days so I can spend as much time as I want, wherever I want. I also think you get a better idea of the culture when you have the time to slow down. For example, I was in Copenhagen for three days and I got to discover parts of the city that were not just the major tourist attractions and those were my favorite parts of the city!...

Another important thing I learned from my trips is that I am absolutely in love with London. Don't get me wrong, the places I am traveling to are incredible, but I am always looking forward to getting back to London. When I get back from my trips, I am overwhelmed with a sense of being home. It is an amazing feeling, knowing I picked the city that was a perfect fit for me.

The reflection is a level 2 (Growing Awareness) which is mostly descriptive with some basic attempts to understand. For example, she discusses understanding her preference to travel more leisurely in order to better "enjoy a new city" and "get a better idea of the culture" by having "time to slow down." She has a sense of London as her new home, but does not explore why in any depth.

This essay is typical of how students often describe their study abroad experiences: through listing sites seen and countries visited. Undoubtedly, the site-seeing is part of the allure of study abroad. It is also often the most accessible component to draw upon; this represents what most people think of when they think of culture - the visible, built, historical markers, the demarcation between new and familiar. The essay shows that, without prompting or framing, the typical approach to reflection is describing travels and expressing emotions. The student does try to draw conclusions (about such things as travel skills or preferences) and tries to show how she has become a Londoner (thinking of London as home), but without an imperative to tie this to the reading or to a prompt, she is unable to connect her experience with theory or draw deep conclusions. 
In contrast, the writing from students in the PRISM section tends to be more thoughtful and analytical. As previously mentioned, students in the PRISM section were instructed to respond to a prompt and incorporate the reading in their reflection essay, and this approach tended to provide students more direction and structure for making sense of their experiences. The following example is representative of the students in the PRISM section. As with the essay above, it was submitted the last week of the semester. This student responded to the prompt, Daydream about the future. How do you see yourself implementing the knowledge, skills, and perspectives you've gained as a part of this experience? What do you want to do next with your life? How will this experience help you in the future? Interestingly, this student also writes about the experience of traveling throughout Europe, but she frames her writing by contrasting the experience of visiting versus staying and understanding:

Upon studying abroad, I realize that traveling can only do so much. After hearing people coming back from weekends away, and looking back on trips myself, I realize that I may be seeing many things, but I am experiencing little.

... How many times have I been to places and only seen, never experienced? The thought frightens me. I have learned how "the ability to deal effectively with others who are culturally different has become a daily necessity" (174). But I have also learned that I don't want to just 'deal' with these people, I want to become a part of these people. I want to integrate myself and become a part of this culture.

Studying abroad has taught me the importance of listening, observing, and the importance of not just visiting but staying. A taste of London may not have brought me back. But this 7 course meal, has left me satisfied, and excited to return. This place has won my heart, and shown me a multitude of cultures. The satisfaction you get when you know about other cultures, and the importance of always having an open mind and heart towards what you don't know. Studying abroad has made me who I am.

While both essays focus on travel, the first one emphasizes the sites visited without trying to make any sense of them or put them into any context. It portrays an individualistic approach of consuming the site, and even the reference to preferring to "spend a longer amount of time in the same city" still means only "spreading out an itinerary over a few days." By contrast, the second essay analyzes and critiques the notion of visiting, stating that perhaps the goal instead should be seeing "what the locals do." The essay even challenges a passage from the reading, defining a more empathetic approach than "to just 'deal' with people;" rather, she says, "I want to become a part of these people." The essay references having obtained the skills of "having an open mind and heart towards what you don't know." While both essays use travel as a framework for cultural learning, the PRISM approach seems to prompt a better articulation of the learning by encouraging analysis, contextualization, and personal growth with framing questions and connections to the reading.

In terms of the second part of the research question, the development of intercultural competence over the course of the semester, results found students in the PRISM section became more skilled at interpreting their experiences in nuanced ways. To show this, I will highlight the type of growth seen in students through a pair of essays from a single student in the PRISM section.

At the start of the semester, most students in the both sections are writing at a level 2 (Growing Awareness) or 3 (Appreciation and Eagerness), meaning they are mostly descriptive, with some 
attempts at interpretation. They are often not quite sure how to make sense of their observations or where to look for more information. The (abridged) essay below is a typical example, responding to the prompt, What is daily life like for the people in your host culture? How is it different from life in the United States?:

I have now been settled down in my host family for about two weeks. I was actually surprised about the amount of space we have. Our family lives in an apartment building. I have a señora, her husband, and they have two grown children, of which I have only met one, because they live on their own. The family has their own living space, with a living room and a small kitchen. The kitchen table only fits three people, therefore my señora will feed us first before feeding her husband and son, if he is there.

... One thing my señora emphasizes over and over is conservation. We are always to turn out the light if we are not directly using it. If we are in the living room, for instance, we should turn off our bedroom lights. The same goes for water. Our showers should be three minutes long. I end up turning off the water in between shampooing and soap so that it saves water.

One of the main differences that we have had to get used to here is the daily schedule ... Meal times also last around an hour. It is not fast or hurried along like in the US. We leisurely eat and then sit and talk with our señora for a little while. We are never quite sure how to decide when to leave after each meal-we are not sure what exactly is appropriate yet. We then take a siesta from 3-5 everyday, along with the rest of town. All of the stores shut down and rest. Dinner isn't until 10pm, and then after that people are out on the streets-babies, children, grandmas, everyone! This daily schedule has taken a lot to get used to, but there are certain things I really love about it!

The student shows Growing Awareness (level 2) by recognizing differences, including observing an emphasis on conservation and a different approach to meals, but does not explore what the other perspective is or how to learn more about it - in fact, she even says, "we are not sure exactly what is appropriate yet." This is typical at the beginning of the semester for students who have not had much intercultural exposure prior to studying abroad and score between a 1-3 on the IES.

As students spend more time abroad, and more time reflecting, it is hoped that they will develop a better sense of understanding, leading to Appreciation and Eagerness (level 3), and even an Emerging Comprehension (level 4). The students in the control section tended to not reach these conclusions or levels of development. By contrast, the PRISM students tended to reach deeper conclusions and articulations of their cultural learning. For example, the same student submitted the essay below at the end of the semester, responding to the prompt, how are you better prepared to be a global citizen because of studying abroad? How bave you been transformed by studying abroad?:

What I took away most about the story of the blind men and the elephant is how they all thought they were right. They stood by their belief about the truth and defended it- they knew a version of the truth, but could not see the whole picture. It made me think how often we do this. We think our religion is right, the food we eat is better, and the way we do life is better. We are willing to defend our beliefs even though we can't see the whole picture. If I had to pick one thing I have learned here, it is that I'm not always right. My lifestyle was shaped by where I grew up and who raised me, and that does not mean it is the only way I 
can live my life. There are so many more possibilities of living and I never need to get worked up when I feel that others are wrong, nor do I have any right to judge anybody's lifestyle as wrong. I like to think of this as flexibility and openness. I want to open in the future to the way other people live. I don't want to be scared of people with different beliefs than I do-and I certainly don't want to be telling them that they are wrong. In "The Problem Solved," I think it makes a great point that our default is to believe that everyone is exactly like us. We assume everybody knows what we consider, "right," when in fact they have their own assumptions about what is right. If I can accept that people won't always react to how I can think, I can use communication to figure out the difference. I have done this with my host mom multiple times - explaining what I have grown up with and then listening to her. In general, communication in relationships, and being open to what the other person says, is incredibly important. I think knowing this will help me be a better friend, daughter, student, and employee one day. Understanding that people react different to me will help me smooth through problems with more ease.

In this reflection, she articulates more in-depth interpretations than her previous reflection. The essay describes a realization that she is "not always right," and an acknowledgement that most people interpret the world in the way they have been taught. The reflection demonstrates an increasing desire to learn through listening and being open. She draws conclusions about openness and communication without fully exploring them, showing an Emerging Comprehension (level 4).

In comparison to her first essay, she shows a more sophisticated sense of understanding about differences (from "We are never quite sure how to decide when to leave after each meal—we are not sure what exactly is appropriate yet" to "If I had to pick one thing I have learned here, it is that I'm not always right") and an increase in curiosity and skills (from just describing differences in routine to using "communication to figure out the difference").

These reflections provide a sampling of the ways the PRISM model provides a structured approach to reflections that helps students deepen their intercultural learning over time. By responding to prompts and incorporating the reading into their reflection essays, students in the PRISM section generally provided essays that more specifically addressed intercultural growth, were more grounded in theory, and better connected their personal experiences to broader themes.

\section{Conclusion}

This research responds to the need for two elements in an intercultural pedagogy: 1) a design for reflection assignments and 2) a rubric for evaluating these reflections. The PRISM assignments provide this design through prompt questions and readings, and the Intercultural Reflection Rubric provides a rubric for evaluating students' writing. This research shows that the PRISM approach of providing prompt questions to guide students' reflection and readings to offer frameworks for interpreting their experiences is an effective approach for student writing, and that Intercultural Reflection Rubric is a useful tool to evaluate intercultural competence in writing.

While the scope of this study is limited, it nonetheless provides a starting point for exploring the approach of structured reflection. No doubt, the freedom of expression and exploration that can result from open-ended writing is highly useful and seems like a logical approach to encouraging student learning abroad. This study shows, however, that for many students, open-ended reflection may not produce thoughtful conclusions, increased curiosity, or improved skillsets. However, when 
given some structure, through readings and prompt questions, students can connect personal experiences to broader frameworks and draw meaningful conclusions about their cultural experiences. In comparison to students who are instructed to simply "reflect on their cultural learning," students who have reflection prompts and instructions to incorporate the readings into their writings produce higher level writing and demonstrate higher levels of intercultural competence over time.

In addition, this research shows the value of the Intercultural Reflection Rubric as a tool for faculty to evaluate and measure students' intercultural development and direct students' learning. By combining best practices in writing with research on intercultural competence, the rubric describes and categorizes intercultural development as evidenced in students' reflective writing, providing markers and evidence of growth.

As study abroad educators seek an intercultural pedagogy to encourage development of intercultural competencies, the PRISM approach and Intercultural Reflection Rubric fill a niche by providing a curricular tool that can be adapted to any intercultural setting and a guide for evaluating student learning. For many students, the critical thinking that is needed to make sense of cultural differences requires some guidance and stimulation. This guidance and stimulation can come through the PRISM framework. The PRISM provides just enough structure to guide students but enough freedom to let their critical thinking and interpretations shine through. The PRISM instructs students to get Prepared, make it Relevant, get Involved, make Sense, and make it Matter, and in particular, having readings to make it relevant and guided questions make sense can help them structure their thinking and reach deeper understandings of their encounters. Through this approach, even students with limited exposure to other cultures prior to studying abroad can be guided through intercultural development and have impactful experiences.

The combination of a curricular tool for guiding students and a rubric for reviewing and evaluating learning is an essential component for the field of intercultural competence. As the use of reflective writing in intercultural settings increases, it is important for educators to have approaches grounded in research. The PRISM approach to reflective writing and the Intercultural Reflection Rubric for evaluating learning are important additions to the development of intercultural learning as an academic field and the creation of an intercultural competence pedagogy.

\section{REFERENCES}

AAC\&U Association of American Colleges and Universities. (2013). Intercultural knowledge and competence VALUE rubric. Retrieved from http://www.aacu.org/value/rubrics/pdf/InterculturalKnowledge.pdf

Alvesson, M., \& Skoldberg, K. (2000). Reflexive methodology: New vistas for qualitative research. London: Sage.

Anderson, P. Lawton, L., Rexeisen, R. \& Hubbard, A. (2006). Short-term study abroad and intercultural sensitivity: A pilot study. International Journal of Intercultural Relations 30(4), 457-469.

Behrnd, V. \& Porzelt, S. (2012). Intercultural competence and training outcomes of students with experiences abroad. International Journal of Intercultural Relations, 36(2), 213-223.

Bennett, J.M. (2009). Transformative training: Designing programs for cultural learning. In M.A. Moodian (Ed.), Contemporary leadership and intercultural competence: Exploring the cross-cultural dynamics within organizations (pp. 95-110). Los Angeles, CA: Sage. 
Bird, A., Mendenhall, M., Stevens, M. J. \& Oddou, G. (2010). Defining the content domain of intercultural competence for global leaders. Journal of Managerial Psychology, 25(8), 810-828.

Boud, D., and Walker, D. (1998). Promoting reflection in professional courses: The challenge of context. Studies in Higher Education, 23(2), 191-206.

Brockbank, A., \& McGill, I. (1998). Facilitating reflective learning in higher education. Berkshire: Open University Press.

Brookfield, S. (1990) "Using critical incidents to explore learner's assumptions". In J. Merziow (ed.) Fostering critical reflection in adulthood: A guide to transformative and emancipatory learning (pp. 177-193). San Francisco: Jossey-Bass Publishing.

Burton, J. (2006). Reflective practice revisited. Work Based Learning in Primary Care 4(4), 297-300.

Chieffo, L. \& Griffiths, L., (2004). Large-scale assessment of student attitudes after a short-term study abroad program. Frontiers: The Interdisciplinary Journal of Study Abroad, 10, 165-177.

Deardorff, D. K. (2006). Identification and assessment of intercultural competence as a student outcome of internationalization. Journal of Studies in International Education, 10(3), 241- 266.

Deardorff, D. K. (2011). Assessing intercultural competence. New Directions for Institutional Research, 2011(149), 65-79.

Duke, S. (2014). Preparing to Study Abroad. Sterling, VA: Stylus Publishing.

Dwyer, M. (2004). More Is Better: The impact of study abroad program duration. Frontiers: The Interdisciplinary Journal of Study Abroad, 10, 151-163.

Finlay, L. (2002). Negotiating the swamp: The opportunity and challenge of reflexivity in research practice. Qualitative Research, 2(2): 209-30.

Finlay, L., and Gough, B. (Eds.). (2003). Reflexivity. A Practical Guide for Researchers in Health and Social Sciences. Oxford: Blackwell.

Fitzgerald, M. (2000). "Establishing cultural competency for health professionals." In V. Skultans \& J. Cox (Eds.) Anthropological Approaches to Psychological Medicine (pp. 184-200). London: Jessica Kingsley Publishing.

Fitzgerald, M. (2001). "Gaining knowledge of culture during professional education". In J. Higgs \& A. Titchen (Eds.), Practice knowledge and expertise in the health professions (pp. 149-156). Melbourne: Butterworth Heinemann.

Gertsen, M.C. (1990). Intercultural competence and expatriates. The International Journal of Human Resource Management, 1(3), 341-362.

Hatton, N. \& Smith, D. (1995). Reflection in teacher education: Towards definition and implementation. Teaching and Teacher Education, 11(1), 33-49.

Hertz, R. (1996). Introduction: Ethics, reflexivity, and voice. Qualitative Sociology, 19(1), 3-9.

Hsiung, P. (2008). Teaching reflexivity in qualitative interviewing. Teaching Sociology, 36(3), 211-26.

Hunter, A. (2008). "Transformative learning in international education." In V. Savicki (Ed.), Developing intercultural competence and transformation: Theory, research, and application in international education (pp. 92-107). Sterling, VA: Stylus.

Huq, J. \& Lewis, L. (2012). From collaboration to campus-wide partnership. International Educator, $21(4), 46-51$.

Jackson, J. (2008). Globalization, internationalization, and short-term stays abroad. International Journal of Intercultural Relations, 32(4), 1-17.

Kehl, K. \& Morris, J. (2007). Differences in global-mindedness between short-term and semester-long study abroad participants at selected private universities. Frontiers: The Interdisciplinary Journal of Study Abroad 15, 67-79.

Kolb, D. (1984). Experiential Learning: Experience as the Source of Learning and Development. Upper Saddle River, NJ: Prentice Hall.

Larivee, B. (2008). Development of a tool to assess teachers' level of reflective practice. Reflective Practice, 9(3), 341-60.

Laws, R. \& Fitzgerald, M. (1997). Intercultural interactions in dietetic practice. Australian Journal of Nutrition \& Dietetics, 54(1), 34-40. 
Lewis, A. (2000). Self-reflexivity and the therapeutic action of psychoanalysis. Psychoanalytic Psychology, 17(4), 667-89.

Lewis, T. \& Niesenbaum, R. (2005, June 3). The benefits of short-term study abroad. Chronicle of Higher Education, 51(39), B20.

McAllister, L., Whiteford, G., Hill, B., Thomas, N. \& Fitzgerald, M. (2006). Reflection in intercultural learning: examining the international experience through a critical incident approach. Reflective Practice, 7(3), 367-381.

Medina-López-Portillo, A. (2004). Intercultural learning assessment: the link between program duration and the development of intercultural sensitivity. Frontiers: The Interdisciplinary Journal of Study Abroad, 10, 179-199.

Mendenhall, M. E., Stevens, M. J., Bird, A., Oddou, G. R., \& Osland, J. (2012). Specification of the content domain of the intercultural effectiveness scale. The Kozai Monograph Series, 1(3), 1-26.

Moon, J. (1999). Reflection in learning \& professional development: theory \& practice. London: Kogan Page.

Moore, D. T. (2010). Forms and issues in experiential learning. New Directions for Teaching and Learning, 2010(124), 3-13.

Oatley, K. \& Djikic, M. (2008). Writing as thinking. Review of General Psychology, 21(1), 9-27.

Olson, C. L., Green, M. F. \& Hill, B. A. (2006). A handbook for advancing comprehensive internationalization: What institutions can do and what students should learn. American Council on Education.

Paige, R. M., Cohen, A. D., Kappler, D., Chi, J. C., \& Lassegard, J. P. (2004). Maximizing Study Abroad. Minneapolis, MN: Center for Advanced Research on Language Acquisition.

Pagano, M. \& Roselle, L. (2009). Beyond reflection through an academic lens: Refraction and international experiential education. Frontiers: The Interdisciplinary Journal of Study Abroad, 18, 217- 229

Pedersen, P. J. (2010). Assessing intercultural effectiveness outcomes in a year-long study abroad program. International Journal of Intercultural Relations, 34(1), 70-80.

Portalla, T., \& Chen, G. M. (2010). The development and validation of the intercultural effectiveness scale. Intercultural Communication Studies, 19(3), 21-37.

Smith, E. (2011). Teaching critical reflection. Teaching in Higher Education, 16(2), 211 - 223.

Vande Berg, M., Paige, R. M., \& Lou, K. H. (2012). Student learning abroad: What our students are learning, what they're not, and what we can do about it. Sterling, VA: Stylus Publishing, LLC.

Vande Berg, M., Connor-Linton, J. \& Paige, R. M. (2009). The Georgetown consortium project: Interventions for student learning abroad. Frontiers: The Interdisciplinary Journal of Study Abroad $18,1-75$.

Wagner, K. \& Magistrale, T. (2000). Writing Across Culture: An Introduction to Study Abroad and the Writing Process. New York: Peter Lang Publishing.

Williams, T. R. (2005). Exploring the impact of study abroad on students' intercultural communication skills: Adaptability and sensitivity. Journal of Studies in International Education, 9(4), 356-371.

Williams, T. R. (forthcoming). Learning through a PRISM: Facilitating Students' Development of Intercultural Competence. Fort Worth, TX: TCU Press. 